\title{
LA RECEPCIÓN DE LA ÉTICA ARISTOTÉLICA \\ EN AVERROES Y SU IMPACTO EN EL MUNDO \\ LATINO MEDIEVAL
}

\section{THE RECEPTION OF THE ARISTOTELIAN ETHICS IN AVERROES AND ITS INFLUENCE ON THE MEDIEVAL LATIN WORLD}

\begin{abstract}
Andrés MARTíNEZ LORCA ${ }^{1}$
Catedrático Emérito de Filosofía de la UNED

Académico de número de la Academia Ambrosiana de Milán (Italia)

Académico Correspondiente de la Real Academia de la Historia
\end{abstract}

Resumen: El pensamiento ético de Averroes apenas ha sido estudiado y ello a pesar de que es el único filósofo islámico medieval del que se conserva un Comentario a la principal obra aristotélica sobre el tema, la Ética nicomáquea. El eje del presente trabajo es precisamente un nuevo análisis de ese Comentario a través de los conceptos de eudaimonía o felicidad, philía o amistad y tò dikaion o justicia.

Averroes subraya los aspectos sociales y políticos apuntados por Aristóteles llegando a considerar el gobierno de los estados uno de los objetivos de su discurso ético. Asimismo, señala la preocupación de los legisladores por buscar la concordia civil que es considerada el mayor bien en las comunidades. Hay, pues, una conexión entre ética y política. Tiene, sin embargo, la hegemonía la política.

Finalmente se considera este aspecto desatendido hasta ahora en la historiografía medieval: fue gracias al pensador andalusí como se produjo en el Occidente latino la recepción de la Ética nicomáquea de Aristóteles, obra que penetró en los círculos filosóficos y también en la cultura bajomedieval. La favorable acogida de los dos

\footnotetext{
1 El presente texto reproduce mi intervención en el Congreso Internacional "Ethics and Politics in the Arab-Islamic Heritage. Ibn Rushd's influence in his time and in later times" celebrado en Marrakech (Marruecos) del 26 al 28 de Abril de 2019. [Para la conversión a artículo de esta conferencia se han eliminado del texto la contextualización y los agradecimientos iniciales. Nota de los editores]
} 
principales teólogos cristianos de la Edad Media, Alberto Magno y Tomás de Aquino, al Comentario de Averroes, traducido al latín por un obispo, ayudó a su difusión en el mundo medieval y más tarde en el Renacimiento.

Palabras clave: eudaimonía, philía, tò díkaion, Ética nicomáquea, La República de Platón, Taljīs kitāb al-Ajlāq de Averroes, Alberto Magno, Tomás de Aquino

AвsTRACT: The ethical thought of Averroes has hardly been studied, and this despite the fact that he is the only medieval islamic philosopher whose Commentary on the main Aristotelian work on the subject, the Nicomachean Ethics, is preserved. The axis of this paper is precisely a new analysis of this Commentary through the concepts of eudaimonia or happiness, philia or friendship and tò dikaion or justice.

Averroes underlines the social and political aspects pointed out by Aristotle, considering the government of the states one of the purposes of his ethical discourse. Likewise, he asserts the concern of legislators to seek civil harmony, which is considered the highest good in the communities. There is, consequently, a connection between ethics and politics. However, politics has the hegemony.

Finally, is considered this neglected aspect so far in medieval historiography: it was thanks to the Andalusian thinker that was produced in the Latin West the reception of Aristotle's Nicomachean Ethics, a work that entered philosophical circles and also late medieval culture. The favorable reception of the two main Christian theologians of the Middle Ages, Albert the Great and Thomas Aquinas, to the Commentary of Averroes, translated into Latin by a bishop, contributed to its spreading in the medieval world and later the Renaissance.

KeYwords: eudaimonia, philía, tò dikaion, Nicomachean Ethics, Plato's Republic, Averroes' Middle Commentary on the Nicomachean Ethics, Albert the Great, Thomas Aquinas.

\section{Introducción}

En contra de la islamofobia que domina en los medios occidentales e incluso en algunos intelectuales que no acaban de cortar con la ideología colonialista, escribí hace años un artículo titulado "La reforma almohade: del impulso religioso

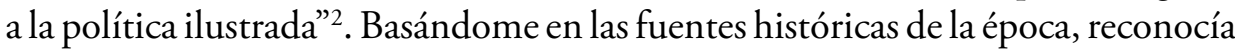

2 Andrés Martínez Lorca, Maestros de Occidente. Estudios sobre el pensamiento andalusí, Madrid, Editorial Trotta, 2007, pp. 46-61. 
este hecho: "como regla general, los gobernantes almohades aparecen como hombres cultos, protectores de los sabios y amantes de los libros", añadiendo por mi parte su estrecha vinculación con al-Andalus. "Recordemos que los tres principales sabios andalusíes de la época, Ibn Tufayl, Averroes y Avenzoar el nieto estuvieron estrechamente ligados a la corte almohade y a su capital, en la que vivieron y donde todos ellos murieron. También se distinguieron los califas almohades por un afecto especial hacia al-Andalus, tierra que protegieron militarmente de los reinos cristianos, a la que viajaron con frecuencia y en cuyo suelo dejaron una magnífica huella urbanística y arquitectónica"3. Por otra parte, he rebatido con argumentos el intento de culpar al «fanatismo de los almohades» de la caída en desgracia que sufrió en su vejez Ibn Rushd, tópico introducido por Renan en el siglo XIX. Como afirmó con su habitual buen sentido Roger Arnaldez, "sería un error histórico creer que él fue perseguido [por los almohades]: de hecho, gozó del favor de los califas" ${ }^{4}$.

Abordar la herencia árabe-islámica con respecto a la ética y la política es un acierto en cuanto puede representar un paso adelante en los estudios averroístas. ¿Por qué razón? Porque se aleja de la recepción medieval de Averroes al situar el foco de las investigaciones sobre su pensamiento en la filosofía moral y política y no en la metafísica. Los escolásticos quedaron deslumbrados por la filosofía aristotélica que llegaron a comprender mediante los Comentarios averroístas más que a través de las traducciones grecolatinas. Profundizaron en algunos campos de la filosofía, como en psicología, metafísica y lógica, pero menospreciaron el estudio de la naturaleza y la filosofía práctica, es decir, relacionada con la acción humana, debido a su propia tradición especulativa y a razones de ortodoxia. Ese limitado horizonte del legado filosófico de Averroes se ha mantenido hasta nuestros días como muestra la escasez de estudios sobre su Ética. Creo que explican esta laguna historiográfica la ausencia de manuscritos árabes, la falta de edición crítica de la versión latina, la carencia de traducciones modernas y la tendencia especulativa heredada de los escolásticos medievales. Continuando en la línea de una nueva hermenéutica de Averroes, como se puede comprobar en mi último libro 5 , me centraré ahora en el análisis de su principal obra de tema ético.

\footnotetext{
3 Ibid., p. 58.

${ }^{4}$ Roger Arnaldez, Averroès, un rationaliste en Islam, París, Éditions Balland, 1998, 2a ed., p. 176.

5 Andrés Martínez Lorca, Hacia un nuevo Averroes. Naturalismo y crítica en el pensador andalusi que revolucionó Europa, Madrid, Editorial UNED, 2017.
} 
Para comprender y valorar el pensamiento ético de Averroes hay que conocer antes la Ética de Aristóteles. Por eso, en un anterior trabajo sobre el tema reflejé en paralelo la posición de ambos tal como se manifiesta en la Ética nicomáquea y en la Paráfrasis averroísta ${ }^{6}$. No repetiré ahora el análisis comparativo textual, pero sí me parece conveniente dibujar el marco general que trazó el filósofo griego, habitualmente oscurecido por una empobrecedora tradición hermenéutica.

\section{Aristóteles, grandes líneas de su Ética}

Aristóteles fue el primero que en Grecia elaboró una teoría del comportamiento humano. Intentó racionalizar algo proteico y cambiante como es la conducta. Siendo consciente de que no se puede pedir el mismo grado de certeza en distintos ámbitos de la realidad, insertó la Ética dentro de las ciencias relacionadas con la acción, la praxis, y de ahí que con expresión ambigua en el lenguaje moderno la llamemos "ciencia práctica". Se opuso al sometimiento de la vida humana a la ciega necesidad del destino, Moîra/Fatum, tan presente en la tragedia griega, abriendo el horizonte a la deliberación, boúleusis, y a la libertad de decisión. Ciertamente, no se delibera de todo, ni de los fenómenos de la naturaleza regidos por la necesidad física, ni sobre el azar o contingencia, týkhè. Sólo deliberamos sobre lo que está en nuestras manos y es practicable o factible. Entre el azar y la necesidad se presenta, pues, la alternativa de la deliberación en base a la cual elegimos.

¿Y qué elegimos, según Aristóteles? Lo que consideramos un bien, no una abstracción, ni una Idea platónica, sino un bien humano tangible. Aunque el bien se dice de muchas maneras, parte siempre del deseo y culmina en el gozo o placer, hèdonế. "Son bienes en uno mismo o fuera de uno mismo, porque no hay más que esto", escribirá en otro tratado ${ }^{7}$. El bien supremo es la felicidad, eudaimonía, concepto de raíz religiosa, eu-dáimon, que él seculariza: consiste en vivir bien y en obrar bien a lo largo de toda una vida e implica vivir en sociedad, poseer bienes externos y desarrollar lo superior en nosotros, la mente, noũs, prefiriendo el modo de vida intelectual, bios theorètikós, al basado en la posesión de riquezas o en el ejercicio del poder ${ }^{8}$.

\footnotetext{
${ }^{6}$ Véase mi trabajo "Acerca de la felicidad y la amistad" en Hacia un nuevo Averroes, cit., pp. 21-67.

7 Aristóteles, Retórica, 1360 b 25-26.

8 "Si, por tanto, la mente, noũs, es divina respecto del hombre, también la vida según ella es divina respecto de la vida humana”: Aristóteles, Ética nicomáquea, X, 7, 1177 b 30-32.
} 
Otro concepto clave en la Ética nicomáquea es el de philía que traducimos como amistad pero que va más allá de lo que habitualmente entendemos por ella. "Es lo más necesario para la vida; sin amigos nadie querría vivir, aun cuando poseyera todos los demás bienes" ". En la Grecia arcaica la philía hacía referencia al clan, a la tribu, es decir, al ámbito de la sangre común. Aristóteles extiende al conjunto de la sociedad ese afecto recíproco: se da la nueva philía entre padres e hijos, entre conciudadanos, entre amantes y entre los que llamamos amigos. La base de ella es la semejanza, una cierta igualdad. Por eso, concluye en un significativo paso que "cuando la distancia es muy grande, como la de la divinidad, la amistad ya no es posible" ${ }^{10}$. En la Ética Eudemia llegará a definir como malos a aquellos que prefieren las cosas a la amistad.

Para que exista armonía social es necesaria la justicia. Dado que todos los humanos no son iguales en su conducta y no pueden dedicarse a lo mismo en su actividad productiva, será ella y más concretamente la llamada por él "justicia política", tò politikón díkaion, la que haga posible la convivencia en la sociedad. Precisando esta perspectiva ética, escribe: "Lo que buscamos no es sólo la justicia sin más, sino la justicia política. Ésta existe entre personas que participan de una vida común para hacer posible la autosuficiencia, personas libres e iguales"11.

Fiel observador de la naturaleza y de la vida social ${ }^{12}$, la Ética aristotélica no olvida el sustrato conflictivo de la acción moral que, desde el terreno de la pasión, el deseo, la voluntad y la deliberación culmina, pero no siempre, en la elección basada en el razonamiento. Otras veces la razón es derrotada por la pasión: "No es posible, o no es fácil, desarraigar con la razón lo que ha arraigado desde siempre en nuestra manera de ser (...). En general, la pasión, páthos, no parece ceder ante el razonamiento, lógō, sino ante la fuerza"13.

Lo que caracteriza la Ética de Aristóteles no es tanto un pretendido finalismo como un sugestivo humanismo. En las líneas finales de su tratado deja clara su propuesta de una "filosofía de las cosas humanas", perì tà anthrốpeia philosohía, que comienza con la Ética y prosigue y culmina con la Política. Ingemar Düring llegó a calificar la Ética nicomáquea como el nacimiento del primer humanismo.

\footnotetext{
9 Aristóteles, Ética nicomáquea, VIII, 1, 1155 a 4-5.

${ }^{10}$ Ética nicomáquea, VIII, 7, 1159 a 4-5.

${ }^{11}$ Ética nicomáquea, V, 6, 1134 a 25-27.

${ }^{12}$ Respecto a esta última, baste como botón de muestra esta aguda observación a propósito del dinero: "el dinero como medida común al cual todo se refiere y con el cual todo se mide", Ética nicomáquea, IX, 1, 1164 a 1-2.

${ }^{13}$ Ética nicomáquea, X, 9, 1179 b 17-18 y 28-29.
} 
Un humanismo en el que se subraya la naturaleza social del hombre y que entrelaza la acción moral con la vida pública, con lo que llamamos política, de tal modo que ésta es la culminación de la ética. Ya en las primeras líneas Aristóteles calificaba su investigación como "una cierta disciplina política" 14 llegando a situar el supremo bien, la felicidad, como el fin al que aspira la política. Primacía, por tanto, de lo público, de lo colectivo, pues el bien del pueblo y de los estados (mal traducido habitualmente como "ciudades" ignorando el sentido más amplio de pólis) es "más hermoso y divino" que el del individuo. En la comunidad política se integran todas las comunidades como partes de ella; lo justo es lo que le conviene a ella ${ }^{15}$.

La Ética nicomáquea fue una obra muy difundida en Europa en la Baja Edad Media y en el Renacimiento. Roberto Grosseteste, obispo de Lincoln, finalizó su traducción directa del griego hacia 1260, aunque existían ya versiones fragmentarias de algunos libros denominadas por los estudiosos Ethica Vetus. Más tarde, el humanista italiano Leonardo Bruni publicó en 1417 una nueva traducción grecolatina del tratado aristotélico, criticada por algunos estudiosos ${ }^{16}$ por su mayor libertad literaria, aunque de indudable éxito editorial en el Renacimiento. En España, donde el griego se ignoraba por completo ${ }^{17}$, se difundieron en el siglo XV varias traducciones en los romances peninsulares (catalán, aragonés y castellano), procedentes sobre todo de la versión de Bruni, a las que se añadió un Compendio de orientación popular ${ }^{18}$.

\section{La transmisión de la Ética nicomáquea en el mundo árabe}

Los sabios musulmanes conocieron ya en el siglo IX el tratado ético de Aristóteles mediante una traducción greco-árabe atribuida tradicionalmente a Ishaq b. Hunayn († 911). Podemos seguir en detalle su huella literaria gracias

14 Ética nicomáquea, I, 2, 1094 b 11.

15 Ética nicomáquea, VIII, 9, 1160 a 8-13.

16 Entre ellos destacó el humanista español Alfonso de Cartagena (1386-1456).

17 El humanista portugués Arias Barbosa afirmaba que "se tenía en Espańa al individuo capaz de articular una palabra en griego por prodigio semejante al de una mula preñada”: Luis Gil, Panorama social del humanismo español, Madrid, Editorial Tecnos, 1997, p. 204.

18 Se ha publicado recientemente una edición de los manuscritos castellanos-aragoneses del siglo XV que conecta con las versiones latinas de la Ética nicomáquea, con las traducciones italianas y catalanas y con los Comentarios de Averroes y Tomás de Aquino: Aristóteles, Compendio de la Ética nicomaquea, edición de Salvador Cuenca Almenar, Zaragoza, Prensas de la Universidad de Zaragoza, 2017. 
al orientalista escocés Douglas Morton Dunlop ${ }^{19}$ que califica dicha traducción como "una extraordinaria realización que muestra en casi todas partes una firme comprensión del complejo pensamiento de Aristóteles" ${ }^{20}$. Los editores de la edición crítica árabe Anna A. Akasoy y Alexander Fidora han publicado el manuscrito único existente en la Biblioteca Qarawiyin de Fez (Marruecos) y la traducción anotada de Dunlop.

"El interés de los árabes en la Ética nicomáquea de Aristóteles comienza hace más de mil años, y ha continuado hasta la época moderna"21. Las más antiguas referencias a la Ética nicomáquea en el mundo árabe se remontan a al-Kindi, en su Epistola sobre el número de libros de Aristóteles y lo que se necesita para alcanzar la filosofía, redactada hacia mediados del siglo IX, y después a al-Farabi en su desaparecido Comentario sobre el tratado aristotélico, así como en diversas obras y especialmente en su Concordia entre el divino Platón y el sabio Aristóteles. Siguen esta orientación hacia la filosofía práctica, al-Amiri, contemporáneo de al-Farabi, en su Libro de la felicidad, quien manejó también el Comentario de Porfirio; Miskawayh en su obra Sobre el refinamiento del carácter, recuperado en nuestra época gracias a la tesis doctoral del arabista Mohamed Arkoun; y el filósofo, astrónomo y matemático persa al-Tusi (†1274) en su obra Ética nasirí, donde comenta el libro de Miskawayh añadiendo un capítulo sobre economía doméstica y otro sobre política.

Si del Oriente islámico pasamos al Occidente, debemos destacar la preciosa referencia del historiador y astrónomo Said al-Andalusi dentro de la biografía de Aristóteles en su meritorio Libro de las categorías de las naciones donde escribió: "Las obras [de Aristóteles] sobre la filosofía práctica se ocupan, por un lado, de la ética y, por otro, de la política. Entre las que tratan de ética se encuentran: su Gran Libro [Ética nicomáquea], escrito para su hijo; su Pequeño Libro [Gran Ética o Magna Moralia, el más breve de los tres], escrito también para su hijo; y

19 The Arabic Version of the Nicomachean Ethics, edición de Anna A. Akasoy y Alexander Fidora, introducción, traducción y notas de Douglas M. Dunlop, Leiden-Boston, Brill, 2005, pp. 1-109. Sigo su reconstrucción cronológica complementándola con la ofrecida por René Antoine Gauthier en su capítulo dedicado a "la Ética nicomáquea en el mundo árabe", Introducción a L'Éthique à Nicomaque, traducción y comentario por R. A. Gauthier y J. I. Jolif, Lovaina-París, Publications Universitaires-Béatrice-Nauwelaerts, 1970, 2a ed., tomo I, pp. 107-111.

20 The Arabic Version of the Nicomachean Ethics, Introducción, p. 2.

${ }^{21}$ Ibid., p. 1. Esta rotunda afirmación de D. M. Dunlop sintetiza bien su visión del tema tras largos años de investigación. 
el que lleva por título Ética Eudemia"22. Los grandes filósofos andalusíes leyeron y comentaron la Ética nicomáquea, el Comentario desaparecido de al-Farabi e incluso un compendio de la Ética nicomáquea de procedencia alejandrina conservado solo en su versión latina con el título de Summa alexandrinorum. Así, Avempace hace un uso frecuente de las teorías éticas de Aristóteles en varias de sus obras, con especial atención en El régimen del solitario; Ibn Tufayl en su novela filosófica El filósofo autodidacto a propósito de al-Farabi y su Comentario; Maimónides usó también la traducción árabe y en su Guía de perplejos desarrolla la concepción aristotélica de la amistad, además de citar el ya mencionado Comentario al-farabiano; pero el filósofo que más valoró la Ética nicomáquea fue el cordobés Averroes en su famosa Paráfrasis que, traducida al latín, renovó el pensamiento ético de la escolástica cristiana, obra en la que nos centraremos más adelante ${ }^{23}$.

Aunque el mundo árabe no llegó a conocer por desgracia la Política de Aristóteles en la Edad Media, sin embargo, sus hombres de ciencia prestaron atención a los problemas ético-políticos preocupados como estaban por mejorar la organización de la sociedad en que vivían. Ello se refleja bien en al-Farabi, principal introductor de Aristóteles y cuyas obras contienen como novedad una teorización islámica de la vida social a la que incorpora elementos de la filosofía griega. Así, por ejemplo, en los siguientes puntos:

- Naturaleza social del hombre. "Imposible que el hombre obtenga la perfección para la que sus dotes naturales fueron creadas a no ser formando sociedades generales y muy variadas donde mutuamente se ayuden y se ocupen unos a favor de otros, de parte de lo que necesitan para vivir" ${ }^{24}$.

- La vida social se basa en la libertad, a diferencia de la naturaleza regida por la necesidad.

- Tipología de las sociedades: perfectas e imperfectas. Son perfectas, el mundo, la nación y la ciudad. Son imperfectas, la aldea, el barrio, la calle y la casa.

22 Said al-Andalusi, Historia de la filosofía y de las ciencias o Libro de las categorías de las naciones, traducción de Eloísa Llavero, Madrid, Editorial Trotta, 2000, p. 86.

${ }^{23}$ Curiosamente, la referencia de Dunlop a este Comentario averroísta es escasa y superficial. En contraposición con Avempace, estudiado minuciosamente en 12 páginas, le dedica a Averroes solo cinco, centradas en un posible préstamo alfarabiano sobre el contenido exacto de los libros que componen el tratado aristotélico.

${ }_{24}$ Abu Nasr al-Farabi, La Ciudad Ideal, traducción de Manuel Alonso, Madrid, Editorial Tecnos, 1985, p. 82. 
- La dirección del Estado. El jefe del Estado ideal debe reunir doce cualidades físicas, intelectuales y morales innatas. De no ser así, el gobernante segundo sería un filósofo. De no hallarse tampoco éste, propone como lo más conveniente una dirección política colegiada inspirada en la filosofía que mantenga la tradición sin perjuicio de introducir las reformas que aconsejen las circunstancias.

- Por la armonía social y contra la violencia entre los individuos y los Estados. "Del propio modo, creen [los defensores de opiniones corrompidas] que los Estados deben luchar y pelear unos con otros entre sí... Cada hombre debe apropiarse todo el bien que hay, debe esforzarse en superar a los otros para sacar de ellos todo el bien que pueda serle útil. El más violento en vencer todo lo que le pone obstáculos, ése es el más feliz. De estas ideas derivan muchas otras en los Estados de opiniones ignorantes. Algunos creen que entre los hombres no hay que buscar ni conexiones ni relaciones, sean éstas naturales o voluntarias. (...) Este es un enorme mal entre las opiniones sobre la humanidad"25.

\section{La concepción de la Ética en el Taljụ̣ kitāb al-Ajlāq}

A más de quince siglos de distancia de Aristóteles, el filósofo cordobés logró, no sin dificultades, disponer del texto íntegro de la traducción árabe de la Ética nicomáquea. Siendo un excepcional estudioso del Corpus aristotélico, le debió parecer un valiosísimo hallazgo llegar a conocer directamente el pensamiento ético del maestro griego. No se trataba solo de un nuevo horizonte teórico sino también de una inestimable ayuda práctica en su faceta de hombre público. En efecto, en paralelo a su actividad filosófica, ocupaba el cargo de juez mayor en al-Andalus, era uno de los consejeros del califa almohade y como médico tenía una especial sensibilidad hacia la vida de las clases populares de al-Andalus como se comprueba en algunas observaciones personales que encontramos en su Enciclopedia médica, el Kulliyat. A diferencia de los teólogos/filósofos escolásticos encerrados en sus monasterios y controlados en su enseñanza por el obispo de la diócesis, celoso guardián de la ortodoxia, los médicos/filósofos árabes desde al-Farabi, Avicena y al-Razi en el Oriente islámico hasta Avempace, Ibn Tufayl y Averroes en el Occidente islámico, intervinieron en la vida social de su época como intelectuales de prestigio y consejeros reales, sufriendo a veces los avatares políticos.

${ }^{25}$ La Ciudad Ideal, p. 115. 
Averroes escribió el Taljịs en plena madurez cuando tenía 51 años. Como señala Dunlop, la traducción greco-árabe que manejó fue "básicamente la misma que se contiene en el manuscrito de $\mathrm{Fez}^{\text {"26 }}$ de la que suprimió un añadido libro séptimo, reduciendo el conjunto de la obra aristotélica a los diez libros originales. Conocemos la fecha exacta en que acabó su redacción, el día 4 de mayo de 1177, según consta en el epílogo. Como informó el arabista Nemesio Morata, la Biblioteca del Real Monasterio de El Escorial poseía dos manuscritos del Taljīs, números 71 y 84, que perecieron en el fuego que quemó parte de esa rica Biblioteca en $1671^{27}$. A juzgar por la procedencia de dichos fondos árabes, es probable su origen magrebí, lo que indicaría su difusión allí, una vez desaparecida al-Andalus. Sólo se conservan fragmentos del original árabe de este Comentario en unas notas marginales a una traducción árabe de la Ética nicomáquea perteneciente a la Biblioteca al-Qarawiyin de Fez y que han sido editados por Berman ${ }^{28}$. El total de fragmentos preservados es de treinta y se distribuyen así: nueve del libro III, diez del libro IV, dos del libro V, uno del libro VII, siete del libro VIII y uno del libro IX. Al texto árabe de Averroes transcrito por el editor le siguen la traducción latina y hebrea.

En un breve período de tiempo, entre 1174 y 1177, produjo una serie importante de Comentarios Medios o Paráfrasis a obras de Aristóteles: Sobre el alma, Metafísica, Retórica, Poética y Ética nicomáquea. Conscientes del valor de estos manuscritos árabes, los latinos tradujeron pronto los Comentarios de Averroes que en algunos casos (Ética, Retórica y Poética) significaron una verdadera revolución en la cultura europea, al conocer así por vez primera las novedosas teorías aristotélicas tanto en el terreno moral como en el literario. Fue gracias al latín como se conoció en Europa el Comentario de Averroes a la Ética nicomáquea de Aristóteles. Esta traducción fue obra del clérigo Hermann el Alemán (muerto el año 1272 siendo obispo de Astorga), que contó con ayuda de mozárabes, como él mismo reconoció. Está fechada en la ciudad de Toledo, centro intercultural por excelencia, el 3 de junio de 1240. Gracias a ella se salvó el magnífico Comentario de Averroes ${ }^{29}$. Se conocen doce manuscritos del

26 The Arabic Version of the Nicomachean Ethics, Introducción, p. 50.

27 N. Morata, "Un catálogo de los fondos árabes primitivos de El Escorial", en Al-Andalus, 2 (1934), pp. 87-181. Este arabista agustino llegó a ser director de la Real Biblioteca de El Escorial.

${ }^{28}$ Lawrence V. Berman, "Excerpts from the lost arabic original of Ibn Rushd's Middle Commentary on the Nicomachean Ethics, Oriens, vol. 20, 1967, pp. 31-59.

${ }^{29}$ Citaremos en adelante el Taljīs por esta edición, de acuerdo con la edición veneciana del siglo XVI: Aristotelis Opera cum Averrois Commentariis, vol. III, Venecia apud Junctas, 1562, reproducida por la Editorial Minerva, Fráncfort del Meno, 1962. Usaré las siglas MNE [in 
Liber Nicomachie, ocho de ellos completos. El Archivo y Biblioteca Capitular de la Catedral de Toledo conserva un valioso ejemplar manuscrito de esta traducción arabo-latina en pergamino de 75 folios y letra del siglo XIII ${ }^{30}$. Este estudioso de origen germánico tradujo también al latín con ayuda de mozárabes los comentarios de Averroes a la Poética y a la Retórica, obras que los árabes integraban en el conjunto de los escritos lógicos aristotélicos que llamamos tradicionalmente Organon. Aunque Hermann reconocía las dificultades del trabajo de traductor y las propias deficiencias en sus versiones arabo-latinas, no dejó por ello de denunciar como lo más bárbaro la simple ignorancia de tales textos filosóficos.

Según Berman, los fragmentos árabes conservados a los que antes aludía no tienen mayor importancia para la versión hebrea que él mismo publicó ${ }^{31}$, ofrecen cierto interés respecto a la erudición árabe medieval y estando fechados en 1222 muestran cómo les atraía a los ilustrados árabes del siglo XIII "una aproximación racional a los problemas de ética y política” como la ofrecida por la Ética nicomáquea ${ }^{32}$. Por otra parte, conviene valorar como se merece este hecho cultural: "la traducción [hebrea] del Comentario Medio de Ibn Rushd indica la primera vez que una obra completa filosófica de ética y política de procedencia directa griega fue traducida al hebreo"33. Samuel ben Judá de Marsella terminó de redactar esa versión hebrea en febrero de 1321. Sabemos de su influencia entre los pensadores judíos medievales, entre los cuales debemos destacar por su clara vinculación averroísta a los sefardíes Yosef ben Sem Tob († hacia 1460) e Isaac Arama. Resulta evidente, como escribe Berman, que Averroes constituyó uno de los principales medios a través de los cuales los judíos cultos asimilaron la filosofía. Unido esto a la simpatía que mostró hacia él el gran pensador judío Maimónides, también cordobés, se comprende que fueran judíos ilustrados quienes brillaran durante la Edad Media y el Renacimiento en la tarea de

\footnotetext{
Moralia Nicomachia Expositione] indicando el libro correspondiente de la Ética nicomáquea en números romanos y el capítulo en números arábigos.

30 Una descripción de este singular manuscrito la ofrece José Ma Millás Vallicrosa en su obra Las traducciones orientales en los manuscritos de la Biblioteca Catedral de Toledo, Madrid, Consejo Superior de Investigaciones Científicas-Instituto Arias Montano, 1942, pp. 67-69.

${ }_{31}$ Averroes' Middle Commentary on Aristotle's Nicomachean Ethics in the Hebrew Version of Samuel ben Judah, ed. Lawrence Berman, Jerusalem, 1999.

32 L. V. Berman, "Excerpts from the lost arabic original of Ibn Rushd's Middle Commentary on the Nicomachean Ethics, cit., pp. 58-59.

33 Lawrence V. Berman, "Ibn Rushd's Middle Commentary on the Nicomachean Ethics in Medieval Hebrew Literature”, en AA.VV., Multiple Averroès, París, Les Belles Lettres, 1978, p. 294.
} 
traducir al latín y al hebreo los Comentarios de Averroes, preservando así su legado literario.

Analizaremos a partir de ahora las líneas generales de la Ética de Averroes centrándonos en sus conceptos fundamentales. En primer lugar, la Ética estudia el comportamiento humano siendo su objeto la acción, no la producción. Por eso, la llamamos ciencia práctica. No se trata aquí de conocer sino de actuar ${ }^{34}$. De ahí la utilidad de ella que pertenece a una ciencia dominante en grado máximo, la política, que consiste en el arte de gobernar los estados ${ }^{35}$. Como el ballestero que dirige sus flechas hacia el blanco, así buscamos el bien perfecto y óptimo de las cosas, que no es un bien individual sino colectivo, pues se refiere al conjunto de los ciudadanos. En este libro tratamos de descubrir ese bien y de conservarlo en la sociedad. "Nuestro propósito en esta exposición es el gobierno de los estados" 36 .

¿Cuál es el sumo bien? La felicidad, responde Averroes siguiendo a Aristóteles. Casi todos los hombres coinciden en nombrar a la felicidad, felicitatem, como aquel bien que busca el arte de gobernar los estados, el bien más excelente y alto de todos los bienes ${ }^{37}$. La felicidad no puede consistir en las riquezas, pues no se buscan por sí mismas sino con vistas a otras $\operatorname{cosas}^{38}$. No es un juego sino algo serio: "la felicidad no consiste en la diversión" 39 . Tampoco se identifica con una idea universal, como pretendía Platón, sin anclaje en el ser humano concreto. Llegamos así a la definición de felicidad: "La felicidad es algo perfecto, suficiente por sí y fin de nuestras acciones" ${ }^{40}$. Pero no se trata de una vida solitaria sino de una vida en común, es decir, con hijos, esposa, parientes y conciudadanos, pues "el hombre es social por naturaleza" ${ }^{41}$. La felicidad es lo más noble de todo y contiene en sí de modo absoluto el placer o deleite, hedonéldelectatio ${ }^{42}$; necesita asimismo de bienes externos y no puede ser feliz el que carece de ellos. La califica también de "lo óptimo entre las cosas y algo divino" ${ }^{43}$. El hombre feliz lleva una vida estable, no sometida al azar, y realiza las acciones virtuosas

${ }^{34}$ Su fin non est scire sed agere: $M N E, \mathrm{I}, 3$.

${ }^{35}$ Ars gubernandi ciutates: $M N E$, I, 2.

${ }^{36}$ Et quod est propositum nostrum in hoc sermone est gubernatio ciuitatum: MNE, I, 3.

37 MNE, I, 4.

$38 M N E$, I, 5.

$39 M N E, \mathrm{X}, 6$.

${ }^{40}$ Felicitas est res perfecta per se sufficiens finis rerum agendarum: MNE, I, 7.

41 Ibid. Est natura ciuilis homo.

${ }^{42}$ MNE, I, 8. Et delectatio absolute existit in ea.

43 [Felicitas] est optima rerum, est quid diuinus: MNE, I, 9. 
a lo largo de toda una vida: "es el más honesto de los hombres aguantando el infortunio sin que ningún vituperio le afecte" ${ }^{44}$. Como ejemplo de resistencia al infortunio, Averroes introduce la literatura bíblica mencionando a Job.

La felicidad perfecta implica la unión entre teoría y felicidad. La felicidad debe hallarse en lo más excelente en nosotros, el intelecto que como él afirma "es la facultad divina o más divina en nosotros” ${ }^{45}$, según explicó en detalle en su Comentario al De anima ${ }^{46}$. ¿En qué consistiría, pues, la felicidad plena? Conectando con el modo de vida intelectual, el bios theorètikós de Aristóteles, Averroes responde que en una actividad de sabiduría y reflexión a lo largo de una vida entera. Si bien el hombre es pequeño de cuerpo, mediante la facultad intelectual supera a los demás seres vivos en capacidad y honor, aspirando a una vida divina y llevando a cabo en la medida de lo posible hechos inmortales, aunque él mismo sea mortal ${ }^{47}$. Concluye esta referencia al modo de vida intelectual con esta reflexión teológica: Dios honrará y beneficiará especialmente a quienes cultivan lo mejor en ellos y aquello que más los aproxima a la divinidad, es decir, el intelecto, "si hay providencia divina respecto a los hombres, como se cree y como se debe" ${ }^{48}$.

En su perspectiva social de la felicidad, subraya la conexión entre ésta y la política. "El verdadero político se ocupa sobre todo de ella [la felicidad], pues quiere hacer a los ciudadanos buenos y obedientes a las leyes", había escrito Aristóteles ${ }^{49}$. Averroes sigue este razonamiento: "Afirmamos en efecto que el fin del régimen de los Estados es más noble, y el máximo deseo en tal régimen es que surjan buenos ciudadanos y que obren el bien" 50 . Y hace suyo el elogio aristotélico de que "el gobierno de los estados es más honorable y mejor que el arte de la medicina" 51 .

\footnotetext{
${ }_{44} M N E, \mathrm{I}, 10$.

${ }^{45} M N E, \mathrm{X}, 7$.

46 Véase mi edición de los principales fragmentos de los tres Comentarios averroístas dedicados al estudio de la facultad racional: Averroes, Sobre el intelecto, edición de Andrés Martínez Lorca, Madrid, Editorial Trotta, 2004.

${ }^{47} M N E, \mathrm{X}, 7$.

${ }^{48} M N E, \mathrm{X}, 8$.

49 Ética nicomáquea, I, 13, 1102 a 8-10.

${ }^{50} M N E$, I, 9.

${ }^{51} M N E, \mathrm{I}, 13$.
} 
Por otra parte, insiste en varias ocasiones en el hecho de que la mayoría de la gente no se inclina al bien por vergüenza sino por miedo al castigo ${ }^{52}$. El mejor medio para fomentar la virtud y el más eficaz instrumento de control social son las leyes. En contra de la opinión de algún estudioso, Averroes no defendió aquí ni en ningún otro texto el absolutismo monárquico de origen teocrático que ya gozaba de predicamento en la tradición feudal europea. Por el contrario, él aboga por la hegemonía de la ley en la vida civil, dado el poder coactivo de ésta dentro de la sociedad que no se fundaba en la arbitrariedad o el capricho sino en "el razonamiento [que] procede de la ciencia y el intelecto" 53 .

La vida humana incluye las acciones de crecimiento y sensación comunes a los otros animales, pero se distingue por una acción propia del hombre, la que está dotada de razón (lógos, razón y lenguaje en Aristóteles). "Y entiendo por esta vida la acción del alma que procede de la deliberación respecto a un fin determinado, y ésta es la acción del hombre excelente o virtuoso" 54 . Interviene aquí de modo decisivo la voluntad, en contra del tópico del fatalismo árabe. Las palabras de Averroes no dejan lugar a dudas en este punto: "Nosotros, sin embargo, buscamos ciertamente en la Ética un bien que puede ser adquirido por nosotros mismos, factible mediante la voluntad, operabile per voluntatem, al ser en efecto esta ciencia la que investiga sobre aquellas cosas cuyo principio es la voluntad y cuyo logro nos pertenece" ${ }^{55}$.

Siguiendo a Aristóteles, Averroes comenta el libro X de la Ética nicomáquea cuyo eje es la crítica a la teoría hedonista del placer defendida por Eudoxo para quien el placer era el bien supremo. El punto de partida de Averroes es realista: muchos son incapaces de distinguir lo que debe hacerse y censuran de palabra los placeres, pero se dejan arrastrar por ellos. Sin embargo, los razonamientos verdaderos valen también para la vida. Propugnando una coherencia moral, afirma que hay que buscar en nuestras acciones una concordancia entre las palabras y los hechos ${ }^{56}$.

Para el filósofo griego ni el placer equivalía al bien, ni todo placer era apetecible en sí, e incluso había cosas por las que nos afanaríamos aun cuando no trajeran

52 MNE, X, 9.

53 Ibid.

${ }^{54} M N E, \mathrm{I}, 7$.

$55 M N E, \mathrm{I}, 6$.

$56 M N E, \mathrm{X}, 1$. 
placer alguno, como ver, recordar, saber y poseer las virtudes ${ }^{57}$. Averroes está de acuerdo en que perseguimos algunas bellas acciones, como la especulación, el razonamiento, el recuerdo y la ciencia, aunque no nos proporcionen placer $^{58}$. "No todo placer es bueno, ni todo es malo, ya que son diversas las formas del placer" $"$.

No deberíamos confundir la teoría aristotélico-averroísta del placer con la represión de las pasiones defendida por los estoicos, para quienes eran movimientos irracionales y perturbadores de la naturaleza que había que extirpar, ni con el ascetismo religioso de los teólogos cristianos. Para el filósofo andalusí el placer va unido a la vida: "quien desea la vida, desea el placer, pues éste perfecciona la vida que elegimos" ${ }^{60}$. A la afirmación aristotélica de que no podemos gozar continuamente, agrega la observación médica que confirma cómo el placer se debilita con los años al perder el vigor juvenil. Repite asimismo este hermoso pensamiento aristotélico: "el placer o deleite del presente está en la misma acción, el del futuro en la esperanza y el del pasado en el recuerdo"61.

Uno de los temas que más ha atraído de la Ética nicomáquea y que más ha perdurado en la literatura posterior ha sido el de la amistad, philía en griego, dilectio en la traducción arabo-latina de Averroes, amicitia en la traducción grecolatina de Aristóteles. El filósofo andalusí recrea aquí con especial complacencia el pensamiento aristotélico, como veremos.

La amistad es lo más necesario para la vida, escribió Aristóteles. "Nadie quiere una vida sin amigos", añade Averroes ${ }^{62}$, que distingue una amistad accidental que puede originarse por placer o interés, de la amistad verdadera y perfecta que se da entre hombres buenos semejantes en virtud ${ }^{63}$. No es frecuente que alguien tenga muchos amigos con amistad perfecta, ni muchos amantes a la vez, ya que los buenos amigos escasean y el amor exige singularidad ${ }^{64}$. La amistad busca una cierta igualdad basada en la proporción y no en el mérito, como ocurre en la justicia $^{65}$, y por eso es imposible ser amigo de la divinidad y resulta muy difícil

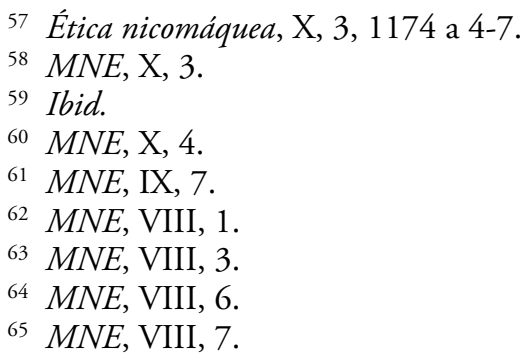


serlo de los reyes. Refiriéndose al ámbito familiar, Averroes critica el gobierno tiránico de los hijos y censura también el gobierno oligárquico en el matrimonio prefiriendo por el contrario en él un régimen aristocrático, es decir, del mejor de ellos, lo que haría posible que gobiernen las mujeres ${ }^{66}$.

Reflejando el realismo aristotélico, Averroes escribe que "todos los hombres o la mayoría de ellos desean lo bello, pero eligen lo útil" ${ }^{67}$. También en este nuevo contexto reitera la preeminencia de la elección en la acción moral: en efecto, la virtud es una cierta elección orientada a una bella acción ${ }^{68}$.

Ya indicamos que para Aristóteles la philía o amistad comprendía lo que hoy entendemos por ésta, así como los diversos niveles del amor (de pareja y materno-paterno filial) e incluso las relaciones laborales y mercantiles, y por eso hablaba de una "amistad civil" y de una "amistad erótica", amatoria en la traducción latina. Averroes acepta esta última distinción y llega a introducir el concepto de "valor» en su referencia al dinero: "Y por esto se ha fijado para todas las cosas en estos Estados una medida común mediante la cual [todo] se mida: y es el dinero, pues por él se conoce el valor de las cosas"69. Claro que el dinero no lo es todo en la vida y como añade Averroes, en un ejemplo significativo, la enseñanza de la filosofía no se paga con dinero sino con el tributo de honor que nos sea posible ${ }^{70}$. Más aun, la falsedad del amigo es peor que la falsificación de moneda, "ya que la amistad es más honorable que el dinero"71.

Al plantearse la conexión entre quien da un beneficio y quien lo recibe, apunta que "el querer es semejante a la actividad, mientras que el ser querido lo es a la pasividad, y la actividad ciertamente es más amorosa que la pasividad: es decir, el que quiere se asemeja al agente, pero el que es querido al paciente"72. En cuanto al amor a sí mismo que Aristóteles proponía más allá del vulgar egoísmo, Averroes lo acepta en quien lleva una vida honorable guiada por el intelecto: "conviene que el hombre virtuoso y bueno sea amante de sí mismo"73.

66 MNE, VIII, 10.

67 MNE, VIII, 13.

${ }^{68}$ Ibid.

69 $M N E$, IX, 1, cursiva mía.

70 Ibid.

${ }^{71} M N E$, IX, 3.

${ }^{72} M N E$, IX, 7.

${ }^{73} M N E$, IX, 8. 
Sobre el número conveniente de amigos, adopta una posición intermedia: no se deben tener excesivos amigos, ni carecer en absoluto de ellos. Dado que la amistad basada en la excelencia o virtud es restringida, "por esto quizá no habrá una multitud de amigos en la amistad perfecta"74. La amistad implica asociación, convivencia, y se mantiene mientras dura la vida como telón de fondo que alegra la existencia humana. "Acaban sus días en aquello que cada uno de ellos quiere, con aquél al que ama entre los que están en el mundo"75.

La Ética de Aristóteles no contiene un código normativo, ni limitaba su reflexión al ámbito de lo privado, ni sostenía un moralismo religioso. Por el contrario, consideraba al hombre como ser social, ligaba la conducta individual a la vida pública y concluía asumiendo en la política, en la acción del Estado, los fines trazados en ella acerca de la felicidad, la excelencia o virtud y la amistad. En esa línea de pensamiento no es de extrañar esta contundente afirmación que sorprenderá a algunos: "Reflexionar sobre el placer y el dolor corresponde al filósofo político" ${ }^{76}$. Averroes, que unía a su labor como filósofo su papel en la vida pública como juez y consejero real, siguió ese camino en su pensamiento ético y lo desarrolló a su modo.

Un concepto clave desde esta perspectiva social es el de la justicia, tò díkaion, que él trata en el capítulo 9 del libro VIII al analizar su relación con la amistad. Para Aristóteles en toda comunidad, koinōnía, hay alguna clase de justicia y también de amistad. "Ahora bien, todas las comunidades parecen partes de la comunidad política. (...) Esto indican los legisladores al decir que lo justo es lo que conviene a la comunidad"77. La perspectiva política de Aristóteles es aceptada sin reservas por Averroes que afirma que "la amistad es una comunidad", amicitia est communitas. Para él se trata aquí de una comunidad ciudadana o civil que busca lo más conveniente al hombre común, conuenientius homini communi, y esto solo se alcanza en el ámbito de lo público, in communicatione publica ${ }^{78}$. Obsérvese en los términos latinos de la traducción la justa comprensión por el filósofo andalusí del pensamiento aristotélico y su interés en subrayar la primacía de lo público y su destinatario último, "el hombre común” o, como dicen los anglosajones en expresión acertada, the man in the street, "el hombre de la calle". Los intereses particulares de los que comercian en el mar o buscan el

\footnotetext{
${ }^{74} M N E$, IX, 10.

75 MNE, IX, 12.

76 Ética nicomáquea, VII, 11, 1152 a 39-b 1.

77 Ética nicomáquea, VIII, 9, 1160 a 8-13.

${ }^{78} M N E$, VIII, 9.
} 
botín de guerra e incluso de los que participan en las fiestas religiosas buscando placer o descanso, se someten al interés público de la sociedad que busca lo más conveniente para todos, no para uno en particular ${ }^{79}$.

En el capítulo 10 del mismo libro VIII plantea las clases de regímenes políticos y su semejanza con el gobierno de la casa. Para Averroes son tres las clases de regímenes políticos: monarquía o realeza, aristocracia y timocracia, a la que la mayoría llamaba régimen constitucional o república, politeía. Y tres también sus desviaciones o corrupciones: la tiranía, la oligarquía y la democracia. En contra de los filósofos del islam oriental, no desaprovecha la ocasión para oponer Platón a Aristóteles a propósito de la dialéctica de la corrupción política: el desarrollo natural de los regímenes se produce como dice Aristóteles y no como creía Platón, subraya ${ }^{80}$.

La amistad en los distintos regímenes políticos es el tema del capítulo 11. Para Aristóteles la amistad entre rey/súbditos, padre/hijos y antepasados/ descendientes se basa en el mérito o superioridad y no en la igualdad. "En las desviaciones [de los regímenes políticos], como apenas hay justicia, tampoco hay amistad, y menos que en ninguna otra, en la peor, la tiranía" ${ }^{1}$. Averroes sintetiza bien el tema: "habrá más amistad allí donde hubiere mayor justicia" y a la inversa, "la amistad es pequeña en los regímenes desviados y mínima en el peor de ellos, la tiranía; en la tiranía, en efecto, nada hay común entre el gobernante y el súbdito" ${ }^{2}$.

¿Puede haber amistad entre amo y esclavo? La pregunta que Aristóteles plantea en esta Ética humanista saca a la luz una cuestión de primer orden en la historia de la humanidad y con frecuencia silenciada, la esclavitud. El filósofo griego distingue: no es posible con el esclavo en cuanto esclavo, ya que ambos nada tienen en común, pero sí en cuanto hombre. Late aquí de modo velado la perspectiva ilustrada introducida por los sofistas al afirmar estos que la esclavitud no existe por naturaleza, phýsei, sino por ley o convención, nómō. El filósofo cordobés amplía el apunte aristotélico y refuerza la posición iniciada por los sofistas. Releamos este significativo fragmento: "No habrá amistad con el esclavo en cuanto esclavo o instrumento animado [definición aristotélica], ya que no hay amistad ni justicia sino a través de una comunidad racional,

\footnotetext{
79 Ibid.: Non quod conuenientius est alicui, sed quod omnibus.

80 MNE, VIII, 10.

81 Ética nicomáquea, VIII, 11, 1161 a 29-32.

${ }^{82} M N E$, VIII, 11.
} 
pero sí la habrá en cuanto que es hombre. Pues se piensa que es necesario que exista alguna justicia entre dos hombres cualesquiera que se relacionan mucho, ya sea en el plano legal, en el contractual o por conveniencia. Inevitablemente habrá amistad entre dos hombres cualesquiera que comparten a su modo lo que hay entre ellos de justicia" ${ }^{83}$. La conclusión resulta llamativa en su época: la amistad será inevitable (dilectio ineuitabiliter erit inter quoslibet duos homines) al compartir los dos, en la medida que sea, la justicia y la racionalidad propia de los intercambios humanos. Averroes se sitúa aquí en una evidente línea ilustrada que, sin llegar a condenar la infame práctica de la esclavitud, resulta insólita en la Edad Media y rara también en los tiempos modernos cuya expansión económica se basó fundamentalmente en la explotación legal de millones de esclavos negros por las potencias colonialistas europeas.

Aristóteles en su concepción de la amistad rompió con el estrecho círculo de la sangre (familia, tribu, clan) que marcaba el territorio del afecto en la Grecia arcaica. "La comunidad es la base de toda amistad", escribió ${ }^{84}$. Averroes ensanchó tal perspectiva al distinguir entre una amistad de consanguinidad y una amistad social, llamando "natural» a la primera y «moral» a la segunda. Por eso, prestó atención a las amistades «civiles y sociales» más allá de la mera amistad basada en los lazos de sangre ${ }^{85}$. Y alabó la concordia que se da cuando los ciudadanos piensan lo mismo sobre lo que más conviene a la generalidad de la sociedad, de lo cual se deriva un gran bien, "como las voluntades civiles comunales" $"$.

\section{EI Comentario de Averroes a la República de Platón}

Para comprender mejor su pensamiento ético-político es necesario considerar también su Comentario a la República de Platón ${ }^{87}$. Como es sabido, el mundo árabe medieval desconoció la Política de Aristóteles, y ello a pesar de la alta estima hacia el filósofo griego y del interés de sus hombres

\footnotetext{
${ }^{83}$ Ibid.

${ }^{84}$ Ética nicomáquea, VIII, 12, 1161 b 11.

${ }^{85} M N E$, VIII, 12.

${ }^{86} M N E$, IX, 6.

87 Averroes, Exposición de la «República» de Platón, traducción y estudio preliminar de Miguel Cruz Hernández, Madrid, Editorial Tecnos, 1986. Cito en adelante esta edición por las siglas ERP.
} 
de ciencia por la organización de la sociedad y el gobierno político. Averroes utilizó la principal obra política de Platón, la República, a falta del texto aristotélico, "ya que el tratado de Aristóteles sobre la Política no ha llegado a nuestras manos" ${ }^{\prime 8}$. Fue uno de sus últimos escritos, redactado hacia el año 1194, es decir, cuatro años antes de su muerte, probablemente como taljīs o exposición. Desaparecido el texto árabe, dependemos de una traducción hebrea llevada a cabo por Samuel ben Judá de Marsella (fechada en noviembre de 1320 y corregida finalmente por él en septiembre de 1321 durante su prisión en el castillo de Beaucaire), y de dos posteriores versiones latinas, una de finales del siglo XV, obra de Elías del Medigo, pensador judío nacido en Creta, y otra de 1539 realizada por el erudito de origen sefardí Jacobo Mantino, muy difundida gracias a las ediciones venecianas de Aristóteles/ Averroes. Hay que agradecer a estos judíos ilustrados que se sentían atraídos hacia el racionalismo de Averroes, y especialmente al traductor provenzal Samuel ben Judá, su transmisión de este texto calificado por Miguel Cruz Hernández en la edición española como "una de las más importantes obras del filósofo cordobés" ${ }^{89}$.

El taljịs se distingue por su originalidad, alejado del tradicional comentario, y por su distanciamiento teórico respecto de Platón. Llama la atención por algunas de sus novedades, entre ellas las siguientes:

- Reduce el Comentario a un tercio del texto griego y prescinde de los libros I (sobre la justicia) y X (sobre la poesía) de la República porque contienen los mitos platónicos y estos "no tienen ningún valor" para él sino solo ofrecen argumentos retóricos o dialécticos.

- Por el contrario, reconstruye con inteligencia el pensamiento ético-político de Aristóteles a través de la Ética nicomáquea y de la Retórica, utilizando también con frecuencia otros escritos de Aristóteles (Metafísica, Física y Sobre el alma).

- Sigue a al-Farabi del que cita varias de sus obras políticas, en el tratado III al tratar de las formas de gobierno.

- Introduce una severa crítica al sistema político andalusí fustigando a los sucesivos gobiernos que habrían pasado de timocráticos a demagógicos para

88 ERP, p. 5.

${ }^{89}$ ERP, p. XI (Estudio preliminar). 
acabar siendo tiránicos. La clase aristocrática es calificada de "totalmente tiránica". Su censura radical a los gobernantes se basa tanto en la ausencia de libertad de los ciudadanos como en la explotación social de las masas: "el poder demagógico en nuestro tiempo a menudo se convierte en tiranía. (...) Las masas son explotadas por los poderosos, y estos progresan apropiándose de los bienes de aquellos, lo que a veces conduce a la tiranía, como sucede en nuestro tiempo y en nuestra sociedad"90. En la persecución que sufrió en su vejez y que culminó con su destierro a Lucena fue determinante sin duda el resentimiento de la oligarquía cordobesa por esa crítica, al que se añadió la hostilidad de alfaquíes rutinarios y ulemas conservadores.

- Dedica su obra al califa almohade de quien afirma que su "concurso para nuestro trabajo ha sido la más perfecta de las ayudas y en todos sus aspectos" ${ }^{1}$. Confirma así su vinculación a la dinastía magrebí que lo protegió junto a otros destacados hombres de ciencia andalusíes.

Su punto de partida, profundamente aristotélico, es éste: la afirmación de la continuidad científica entre la Ética y la Política, ambas ciencias prácticas cuyo objeto es la acción, estudiando la primera las costumbres y hábitos desde un punto de vista general y la segunda la organización de las costumbres en los grupos sociales desde un punto de vista más concreto y particular ${ }^{92}$. Por esto llama a la Ética "primera parte de esta ciencia"93 cuya culminación o segunda parte es la Política. Veamos ahora los fundamentos de la Ética que expone en el tratado I.

Parece imposible que un hombre alcance por sí solo todas las virtudes. La perfección humana e incluso la propia supervivencia (procurarse alimento, alojamiento y vestido) hacen necesaria una existencia social, la vida en común. "Por esto el hombre es por naturaleza político" 94

La acción humana es libre y se desarrolla en el seno de la sociedad. Dado que ésta se encuentra dividida en distintas clases sociales, algunas virtudes son propias de una clase concreta mientras que la justicia, que tiene la primacía, debe armonizar el conjunto. El camino para alcanzar las virtudes morales o

\footnotetext{
90 ERP, pp. 132 y 110-111, cursiva mía.

91 ERP, p. 148.

92 Aristóteles expone esta conexión al final de la Ética nicomáquea, X, 9.

${ }_{93} E R P$, p. 5. Esta perspectiva de Averroes cobra mayor valor si tenemos en cuenta que el mundo árabe medieval no llegó a conocer la Política de Aristóteles.

94 ERP, p. 6.
} 
éticas (liberalidad, templanza, fortaleza y justicia) es el hábito, y el camino para lograr las virtudes intelectuales o dianoéticas (sabiduría, inteligencia y prudencia) es el estudio. Tres breves reflexiones perfilan su teoría de las virtudes ${ }^{95}$ :

a) La realización de la virtud necesita de unas condiciones concretas y de un conocimiento adecuado para la acción.

b) Las virtudes deben inculcarse desde jóvenes y conservadas una vez que hayan sido perfeccionadas.

c) Hay que conocer bien los fines de las perfecciones y su aplicación social, como sucede en la práctica médica.

Las vías mediante las cuales la virtud se inculca y desarrolla en los ciudadanos son éstas: la convicción por medio de la dialéctica, la retórica y la poética, ya que la mayoría de la gente no puede ser instruida con argumentos demostrativos, y mediante la coerción y el castigo. En una sociedad ideal debe reducirse al mínimo el recurso a la disciplina por medio de la coerción ${ }^{96}$.

Alejándose de la estructura formal del Comentario, es decir, de la literalidad del texto platónico, Averroes introduce algunas críticas internas centradas en la sociedad islámica a la que pertenecía. Así, refutó el voluntarismo de los teólogos especulativos islámicos ${ }^{97}$, los mutakallimūn; rechazó una visión interesada y vulgar de la vida moral que se reduciría según él a "supersticiones" y "representaciones inadecuadas de la felicidad eterna" 98 ; y censuró con dureza a los regímenes políticos islámicos, desde una perspectiva ilustrada que no admitía lo que Yabri llamó «la sacralización de la política». "Las comunidades de muchos de los reyes musulmanes de hoy son casi exclusivamente asociaciones de estrictos clanes y las normas que siguen vigentes en ellas son las que les permiten mantener las leyes primarias" 99 .

95 ERP, pp. 9-10.

96 ERP, pp. 11-12.

97 ERP, p. 20.

98 "La inclinación a muchas de las virtudes nobles queridas en razón de ideas miserables, como la mayoría de las supersticiones que se refieren a la recompensa eterna como estrictos placeres sensibles, hacen que un hombre quiera ser valiente, justo y veraz y que se le llame virtuoso porque puede cohabitar, beber y comer": ERP, p. 21.

99 ERP, p. 110. 
Llama la atención en este Comentario su reflexión sobre el papel social de la mujer. Averroes comenta aquí la propuesta de Platón respecto a la educación de la mujer en la clase social de los guardianes, pero va más allá que el filósofo ateniense ya que no la reduce a una clase social, sino que la extiende al conjunto de la sociedad. Partiendo de una capacidad humana genérica, común tanto a los hombres como a las mujeres, concluye de ahí la más alta cualificación femenina cuando se han dado circunstancias favorables: “... la mujer, en tanto que es semejante al varón, debe participar necesariamente del fin último del hombre, aunque existan diferencias en más o en menos. (...) Cuando algunas mujeres han sido muy bien educadas y poseían disposiciones sobresalientes, no ha resultado imposible que lleguen a ser filósofos y gobernantes" ${ }^{100}$.

El filósofo andalusí culmina este pasaje con una severa denuncia de la discriminación social de la mujer en la sociedad de su tiempo: "Sin embargo, en estas sociedades nuestras se desconocen las habilidades de las mujeres, porque en ellas sólo se utilizan para la procreación, estando por tanto destinadas al servicio de sus maridos y relegadas al cuidado de la procreación, educación y crianza. Pero esto inutiliza sus otras posibles actividades. Como en dichas comunidades las mujeres no se preparan para ninguna de las virtudes humanas, sucede que muchas veces se asemejan a las plantas en estas sociedades, representando una carga para los hombres, lo cual es una de las razones de la pobreza de dichas comunidades"101. Que este contundente alegato a favor de los derechos de la mujer fuera redactado en el siglo XII nos llena de admiración por la novedad de su planteamiento así en el islam como en el Occidente cristiano.

Por último, reafirma aquí la hegemonía de la política en el ámbito de la filosofía práctica ${ }^{102}$ y señala la cohesión social como el principal objetivo político: "no existe peor mal en el gobierno social que aquella política que hace de una sola sociedad varias, al igual que no hay mayor bien en las comunidades que aquello que las reúne y unifica"103.

\footnotetext{
100 ERP, pp. 57-58.

101 ERP, p. 59.

102 ERP, p. 89.

${ }_{103}$ ERP, p. 64.
} 


\section{La influencia del Comentario de Averroes a la Ética nicomáquea en el pensamiento escolástico}

Los filósofos musulmanes marcaron el rumbo de la Escolástica latina. Por una parte, por su mayor desarrollo en algunos campos concretos como la Lógica (al-Farabi), la Metafísica (Avicena y Averroes) y la Psicología (Averroes); y por otra, por haber recuperado la ciencia griega, en especial la filosofía de Aristóteles, a través de las traducciones greco-árabes y de sus propios Comentarios. El filósofo islámico que más influyó en la filosofía y teología cristianas de la Baja Edad Media latina fue el cordobés Averroes. Aquí intentaremos rastrear la huella latina de su Comentario a la Ética nicomáquea.

Los dominicos, nueva orden religiosa asentada en las ciudades y que prestó atención al árabe y al hebreo en sus escuelas llamadas Studia linguarum, acogieron favorablemente los libros de Averroes. A través de sus maestros que enseñaban en la universidad de París contribuyeron a expandir su pensamiento.

El primer dominico que leyó los Comentarios de Averroes fue el alemán Alberto Magno (1200-1280), teólogo y filósofo de primer orden, autor de una valiosa bibliografía y maestro de Tomás de Aquino. Hay que situarlo en una línea de recuperación del naturalismo aristotélico e incluso de avance decidido en el método experimental. Era lógico, pues, que sintonizara intelectualmente con el filósofo andalusí, como él mismo reconocía: "Nos autem in paucis dissentimus ab Averroes", "nosotros discrepamos de Averroes en pocas cosas" 104 .

Sigue en general a Aristóteles, especialmente en su teoría de las virtudes. Averroes es citado expresamente en 59 ocasiones a las que el editor alemán ańade otras 45 citas más, lo cual es significativo. Atraído por el tratado aristotélico, hacia 1250 impartió un curso sobre él en Colonia que posteriormente redactó su discípulo Tomás de Aquino en una intensa labor como secretario basándose en las notas que se han conservado. Existen al menos seis manuscritos de Lectura in Libros Ethicorum que contiene 502 Cuestiones y cuya influencia en el Comentario tomista resulta evidente tanto en el aprovechamiento de los Comentarios griegos ahí recogidos como en el texto latino de la Ética nicomáquea usado e incluso en su estilo literario.

104 Alberto Magno, De anima, III, 3. 
Para algunos reconocidos estudiosos como R. A. Gauthier, éste es el mejor Comentario medieval sobre el tratado aristotélico. Casi veinte años más tarde, escribió un segundo Comentario, Commentarium in X Libros Ethicorum ${ }^{105}$, del que entresacaré algunos puntos de interés.

El fin de la política no es saber, scire, sino obrar, operari, y por eso se la llama ciencia práctica, escribe Alberto Magno. Aunque un uso imperfecto de ella puede darse sin teoría, el uso propio de la ciencia exige considerar la razón de las acciones, fundarla sobre la teoría ${ }^{106}$. A diferencia de Aristóteles, él afirma que la política es subalterna de la ética, ya que la política se ordena a la felicidad y ésta es esencialmente obra de la virtud que pertenece así al ámbito moral ${ }^{107}$. Al recordar más adelante que había reconocido que era una ciencia principalísima, matiza sus palabras ańadiendo que "se dice que la política es principalísima respecto de las artes mecánicas que se ordenan a las funciones del Estado, pero no respecto de la moral" ${ }^{108}$.

La legislación es parte de la política y se reduce a tratar las distintas tareas civiles, mientras que ésta atiende también las diversas clases de regímenes políticos y de constituciones. Pero esta filosofía humanista, quae est circa bumana, abarca no solo la ética y la política sino también la económica, "que ciertamente es posterior en rango a la política, en cuanto que el régimen de la casa, oikí, domus, se toma por su semejanza con el régimen del Estado, civitatis, (...) aunque según el orden natural la casa es anterior al Estado, y no observa Aristóteles el orden de la naturaleza, sino el de la teoría"109.

En otro plano, el teólogo alemán distingue la política de la retórica al situar aquélla, como ya vimos, entre las ciencias prácticas, mientras que ésta tiene un carácter instrumental, pertenece al lenguaje, es sermocinalis. Por otra parte, la política perfecta no se logra con un conocimiento universal sino cuando éste se aplica a unas acciones particulares. "De donde resulta evidente que aquellos que no son expertos en los asuntos civiles, no pueden ser políticos ni poseer la

\footnotetext{
105 Alberto Magno, Super Ethica commentum et quaestiones, edición de Wilhelm Kübel, en Id., Opera Omnia, vol. XIV, tomo I, Monasterio de Wesfalia, Editorial Aschendorff, 19681972, que contiene los cinco primeros libros; y tomo II, que contiene los libros VI-X, en la misma editorial, 1987. Lo cito más adelante por las siglas $S E$ indicando el libro en números romanos y la lectio.

106 SE, tomo II, X, lectio 19, p. 789.

107 Ibid.

108 Ibid., p. 790.

109 Ibid., pp. 790-791.
} 
ciencia política de un modo perfecto, porque el político es alguien operativo y porque nadie puede enseñar sino aquello que sabe" ${ }^{110}$.

Tomás de Aquino (1224-1274), también dominico, maestro prestigioso en la universidad de París, de inmensa producción literaria filosófico-teológica, elaboró un fecundo pensamiento que hunde sus raíces en el aristotelismo. La expansión y consolidación de la fama de Averroes en el mundo latino se debe en gran parte a él. Quien llegaría a convertirse en el más importante teólogo cristiano dio así el merecido reconocimiento público a un pensador musulmán mirado con desconfianza, si no con hostilidad, en los medios universitarios controlados por la jerarquía eclesiástica, entre ellos en la facultad de teología de París. Creo que llevaba razón L. Gardet cuando escribió que lo que fray Tomás iba buscando en los minuciosos análisis del Comentador y en su aristotelismo de base era "un perfeccionamiento del utillaje filosófico"111. Le debemos a Salvador Gómez Nogales una buena reconstrucción de esa influencia en el dominico italiano ${ }^{112}$.

En un elaborado artículo V. J. Bourke ha subrayado con acierto que el legado árabe le mostraba al teólogo italiano la posibilidad de incorporar la Ética aristotélica a su propia perspectiva religiosa. A diferencia de otros filósofos islámicos, "fue el Comentario Medio de Averroes sobre la Ética el que fue bien conocido por el Aquinate. Hay más de 30 pasajes en el Comentario tomista que muestran alguna relación con el pensamiento de Averroes. Por supuesto, es bien conocido que el estilo del Comentario a la Ética de Tomás de Aquino es similar a los Comentarios Medios averroístas. En un análisis final, la lección más importante que Tomás habría aprendido de los Comentadores árabes es que la Ética aristotélica no es completamente incompatible con una consistente posición teísta" ${ }^{113}$. A pesar de admitir que el presente Comentario es uno de los más simples y menos pretenciosos de él, lo comparó con ventaja con la mayoría de los publicados a finales del siglo XIX e inicios del XX, ya que estos habían sido escritos por quienes ni eran filósofos, ni conocían a fondo el pensamiento aristotélico $^{114}$.

110 Ibid., pp. 791-792.

111 Louis Gardet, "Saint Thomas et ses prédécesseurs arabes", en St. Thomas Aquinas. Commemorative Studies, Toronto, Pontifical Institute of Mediaeval Studies, 1974, vol. I, p. 437.

112 Salvador Gómez Nogales, "Saint Thomas, Averroès et l'averroïsme”, en Aquinas and problems of his time, Lovaina, Leuven University Press-The Hague Martinus Nijhoff, 1976, pp. 161-177.

113 Vernon J. Bourke, “The Nicomachean Ethics and Thomas Aquinas", en St. Thomas Aquinas. Commemorative Studies, cit., vol. I, p. 244.

114 Ibid., p. 259. 
Donde mejor podemos rastrear esa huella aristotélico-averroísta es en su Comentario a la Ética nicomáquea titulado Sententia libri Ethicorum ${ }^{115}$, que tanto influyó en la Escolástica posterior. Ya al comienzo, tras distinguir una triple filosofía (natural, racional y moral), afirma que "el hombre es naturalmente un animal social"116. El objeto de la filosofía moral es la acción del hombre (prãxis, en griego) y por eso habla aquí de "razón práctica". En el capítulo 2, de especial interés, Aristóteles consideraba a la política como ciencia principal y eminentemente directiva. Fray Tomás, por su parte, afirma que la política o civilis scientia es "principalísima y arquitectónica en grado máximo, y a ella corresponde considerar el fin óptimo de la vida humana"117. En cuanto tal, es directiva o hegemónica tanto respecto a las ciencias especulativas como a las prácticas. Se distancia, sin embargo, del filósofo griego al advertir que esa superioridad de la política queda restringida al ámbito de las ciencias que tratan de las cosas humanas, ya que la "ciencia divina" o teología es principalísima en sentido absoluto al especular sobre "el último fin de todo el universo" 118 . Concuerda, no obstante, con él en considerar mayor y más perfecto el bien de toda la sociedad que el de un individuo pues siendo bueno éste, "mucho mejor y más divino, melius et divinius, es el que afecta al conjunto del pueblo y a los estados"119.

La felicidad representa el supremo bien al que aspira la política ${ }^{120}$. A la vida placentera no sólo se inclina la gente común sino también algunos del mayor prestigio por su calidad científica o su honestidad de vida, entre los cuales menciona sorprendentemente a los epicúreos que al tiempo que "consideraban el placer o deleite como sumo bien, practicaban las virtudes de manera diligente"121. La felicidad humana no puede ser la misma que la de los animales que disfrutan del placer de la comida y del coito. Tampoco consiste en la riqueza "que se adquiere por la violencia y se pierde por ella". El modo de vida intelectual o teorético radica, por el contrario, en la búsqueda de la razón teórica, en la contemplación de la verdad ${ }^{122}$.

115 Tomás de Aquino, Sententia libri Ethicorum, edición de R. A. Gauthier en Id., Opera Omnia, Edición Leonina, tomo XLVII, vol. I, libros I-III, Roma, Santa Sabina, 1969. Cito en adelante por las siglas $S L E$, seguida del libro y capítulo.

116 Tomás de Aquino, SLE, I, 1: homo naturaliter est animal sociale.

117 SLE, I, 2.

118 Ibid.

119 Ibid.

120 SLE, I, 4.

121 SLE, I, 5.

122 Ibid. 
En los capítulos 6, 7 y 8 de este libro I considera desde un punto de vista crítico el Bien platónico. Siguiendo a Aristóteles, muestra que no existe una idea general de Bien y que incluso si existiera, no consistiría en ella la felicidad humana. Por otra parte, el Bien se predica por analogía, no de modo unívoco. Además, el Bien separado platónico resultaría inútil por completo para las ciencias y las artes, pues ni sería provechoso para adquirir el conocimiento científico ni para el ejercicio concreto de cualquier arte ${ }^{123}$.

Sobre la felicidad: es algo perfecto y suficiente, pues es el fin último de las acciones humanas. Llegado a este punto, Tomás de Aquino estima necesario alejarse del naturalismo aristotélico e introducir la perspectiva cristiana. "El Filósofo [Aristóteles] habla en este libro de la felicidad que se puede alcanzar en esta vida; ya que la felicidad de la otra vida excede toda indagación racional" ${ }^{124}$. Más adelante, vuelve a distanciarse de Aristóteles al distinguir a Dios, totale bonum, del bien perfecto humano. "Nada es bueno sino por el hecho de que participa de la bondad divina" 125 .

Como el hombre es un animal político, ha nacido para convivir con los demás. El que es feliz no puede vivir solo, lo que entrañaría una posición radicalmente opuesta a los eremitas y al monacato cristiano. Tomás de Aquino comenta aquí el pasaje aristotélico sin introducir crítica alguna ${ }^{126}$. La convivencia humana podría definirse como un intercambio de palabras y pensamientos. Esta vida es propiamente humana y no el comer juntos como ocurre en el ganado ${ }^{127}$.

La ley es necesaria por su fuerza coactiva pues la mayoría de los hombres se guían más por la pasión que por la razón. "Tiene fuerza coactiva en cuanto es promulgada por el rey o gobernante, y es una orden que procede de alguna prudencia e intelecto dirigido al bien" ${ }^{128}$. El legislador debe ser de modo prioritario una persona pública y necesita de la ciencia, del conocimiento universal ${ }^{129}$. En el capítulo que cierra este Comentario incluye estas breves reflexiones: la legislación es una cierta política arquitectónica; el mejor legado que pueden dejar los políticos es hacer buenos ciudadanos; para llegar a ser

123 SLE, I, 6-8.

$124 S L E$, I, 9. Otras referencias a la felicidad en la vida futura como felicidad perfecta: I, 9; I, 15; II, 16; X, 13.

125 Ibid.

126 Sententia libri Ethicorum, vol. II (libros IV-X), VIII, 12.

127 SLE, IX, 11.

128 SLE, X, 14.

129 SLE, X, 15. 
político hace falta experiencia ${ }^{130}$. En estas líneas finales demuestra conocer bien la Politica de Aristóteles. He estudiado a fondo este novedoso Comentario tomista en un libro que acaba de editarse ${ }^{131}$.

Como hemos visto, Tomás de Aquino acepta las líneas generales de la Ética aristotélico-averroísta: la teoría de la virtud (aretế, virtus) y sus clases, el concepto de felicidad (eudaimonía, felicitas), la amistad (philía, amicitia) como esencial para la vida humana, el hombre como ser social y político. Su actitud ante la Ética humanista de Aristóteles era más abierta de lo que muchos suponen. Por otra parte, el influjo de su maestro Alberto Magno queda patente al verificarlo, como ha hecho R. A. Gauthier, en 350 pasajes de su Comentario.

Resumamos ahora la teoría ético-política del gran teólogo cristiano. El sugestivo programa de una "filosofía de las cosas humanas» esbozado por Aristóteles en la Ética nicomáquea y desarrollado en la Política encontró en Tomás de Aquino una calurosa acogida. La hegemonía de la política sobre las demás ciencias y la naturaleza social del hombre (dos principios básicos del pensamiento aristotélico) fueron asimiladas tan profundamente por él que no vaciló en aceptar sus más radicales consecuencias. Algunas de ellas las encontramos expuestas en el prólogo a Sententia libri Politicorum: el Estado como la comunidad humana más perfecta, la política en cuanto perfeccionamiento de la filosofía, la ciencia política como arquitectónica respecto a las demás ciencias morales. Otras se hallan dispersas en muy diversos escritos tomistas: así, el llamativo reconocimiento del hombre como «animal civil o político» incluso en el paraíso terrenal, al no representar la política una secuela del pecado original sino una característica esencial del orden de la naturaleza (Summa Theologiae); la atribución del fin último de la vida humana, la felicidad, a la política (Sententia libri Ethicorum); y la afirmación de la política como más honorable que la medicina y cuyo conocimiento exige experiencia (Tabula libri Ethicorum).

En definitiva, la recepción de la Ética de Aristóteles, su difusión en las universidades europeas y su posterior asimilación en el mundo bajomedieval y renacentista se debió fundamentalmente al atractivo horizonte teórico que trazó el filósofo griego sobre la conducta humana y también, y de modo decisivo, al Comentario de Averroes a la Ética nicomáquea. La favorable acogida al

\footnotetext{
130 SLE, X, 16.

131 Tomás de Aquino, Exposición de la Politica de Aristóteles [Sententia libri Politicorum], traducción de Pedro Roche Arnas, revisión, prólogo, introducción y notas de Andrés Martínez Lorca, Madrid, UNED, 2019. Véase en especial mi Introducción, pp. 15-58.
} 
pensamiento ético aristotélico-averroísta por los principales teólogos cristianos, Tomás de Aquino y Alberto Magno, abrió el camino a su penetración en la cultura europea. Es una paradoja que haya sido el mundo latino el receptor del Comentario de Averroes y el difusor de su pensamiento ético, heredado de Aristóteles. También fue un destino paradójico, como señaló L. Gardet, que habiendo sido conocido Ibn Rushd en el mundo islámico sobre todo como jurista, "es a través de Occidente cómo el islam contemporáneo ha redescubierto a Ibn Rushd como filósofo" 132 . Comparto la queja que expresaba R. Arnaldez: "Es cierto que Averroes merecía, en la historia del pensamiento islámico, un destino diferente al que conoció" 133 .

Averroes representó como ningún otro hombre de ciencia medieval el racionalismo filosófico, el naturalismo científico y una concepción de la religión islámica abierta al pensamiento ilustrado y a la sociedad de su época. Por eso, cuando recordamos su figura y releemos sus escritos no hacemos un trabajo arqueológico, sino que vemos en su extraordinaria obra un pensamiento abierto al futuro, así en el mundo árabe como en el llamado mundo occidental que tanto aprendió de su legado cuando renacía de la barbarie anterior.

\section{Bibliografía}

Aristóteles, Ética a Nicómaco, edición bilingüe y traducción por María Araujo y Julián Marías, Madrid, Instituto de Estudios Políticos, 1970.

Aristote, L'Éthique à Nicomaque, introducción, traducción y comentario de R.A. Gauthier y J.I. Jolif, Lovaina-París, Publications Universitaires- B. Nauwelaerts, 1970, dos tomos.

Aristóteles, Compendio de la Ética nicomaquea, edición de Salvador Cuenca Almenar, Zaragoza, Prensas de la Universidad de Zaragoza, 2017.

The Arabic Version of the Nicomachean Ethics, introducción, traducción y notas de Douglas M. Dunlop, edición de Anna A. Akasoy y Alexander Fidora, Leiden-Boston, Brill, 2005.

Averroes, In Moralia Nicomachia Expositione, en Aristotelis Opera cum Averrois Commentariis, Venecia, apud Junctas, 1562, vol. III, reproducido por la Editorial Minerva, Fráncfort del Meno, 1962.

132 L. Gardet, "Saint Thomas et ses prédécesseurs arabes", cit., p. 439.

133 R. Arnaldez, Averroès, un rationaliste en Islam, cit., p. 177. 
Averroes, Exposición de la «República» de Platón, traducción y estudio preliminar de Miguel Cruz Hernández, Madrid, Editorial Tecnos, 1986.

Alberto Magno, Super Ethica commentum et quaestiones, edición de Wilhelm Kübel, en Alberti Magni Opera Omnia, vol. XIV, tomos I y II, Monasterio de Wesfalia, Editorial Aschendorff, 1968-1972.

Tomás de Aquino, Sententia libri Ethicorum, edición de R. A. Gauthier en Sancti Thomae de Aquino Opera Omnia, Edición Leonina, Roma, Santa Sabina, 1969, tomo XLVII, vols. I y II.

Tomás de Aquino, Exposición de la Politica de Aristóteles [Sententia libri Politicorum], traducción de Pedro Roche Arnas, revisión, prólogo, introducción y notas de Andrés Martínez Lorca, Madrid, UNED, 2019.

AA.VV., Multiple Averroès, París, Les Belles Lettres, 1978.

Roger Arnaldez, Averroès, un rationaliste en Islam, París, Éditions Balland, $1998,2^{a}$ ed.

Andrés Martínez Lorca, Hacia un nuevo Averroes. Naturalismo y critica en el pensador andalusí que revolucionó Europa, Madrid, UNED, 2017.

St. Thomas Aquinas, Commemorative Studies, Toronto, Pontifical Institute of Mediaeval Studies, 1974, vol. I.

Aquinas and problems of his time, edición de G. Verbeke y D. Verhelst, Lovaina, Leuven University Press-The Hague Martinus Nijhoff, 1976.

Recibido: $15 / 5 / 2019$

Aceptado: 20/10/2019

Este trabajo se encuentra bajo una licencia de Creative Commons Reconocimiento-NoComercial-SinObraDerivada 4.0 